\title{
Cu-Doped Carbon Dots as Catalysts for the Chemiluminescence Detection of Glucose
}

Yan Duan, ${ }^{\dagger, 1}$ Yijun Huang, $,{ }^{\dagger}, 1$ Shengyu Chen, ${ }^{\dagger}$ Weiyuan Zuo, ${ }^{\dagger}$ Bingfang Shi ${ }^{\dagger}, *$

${ }^{\dagger}$ Key Laboratory of Regional Ecological Environment Analysis and Pollution Control of West Guangxi, College of Chemistry and Environmental Engineering, Baise University, Baise 533000, China

* State Key Laboratory Breeding Base of Nonferrous Metals and Specific Materials Processing, College of Materials Science and Engineering, Guilin University of Technology, Guilin 541004, China 


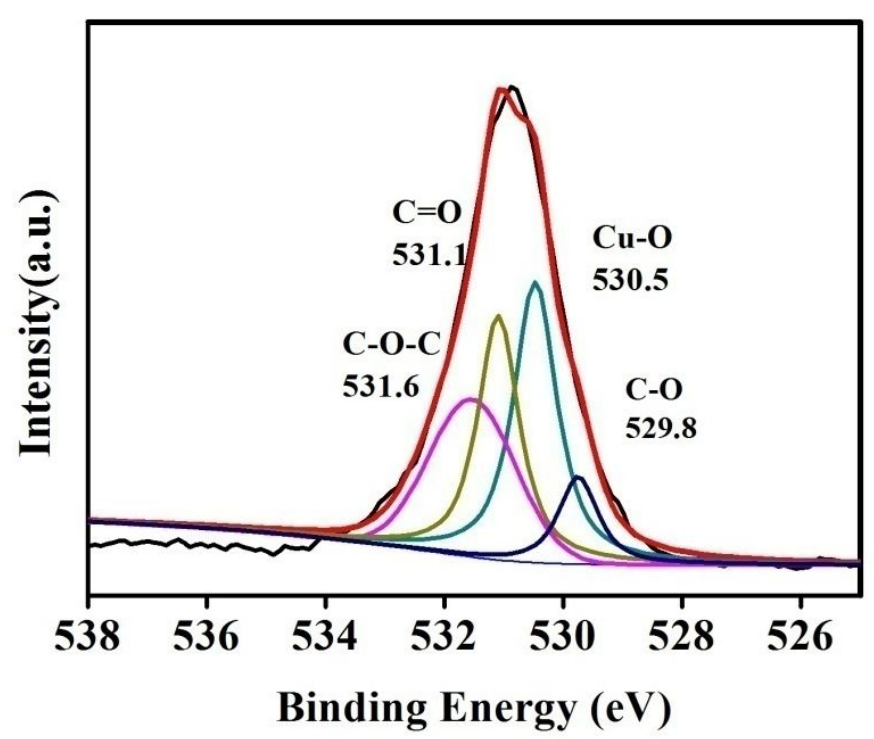

Figure S1. XPS High-Resolution Survey of o1s of Cu-CDs.

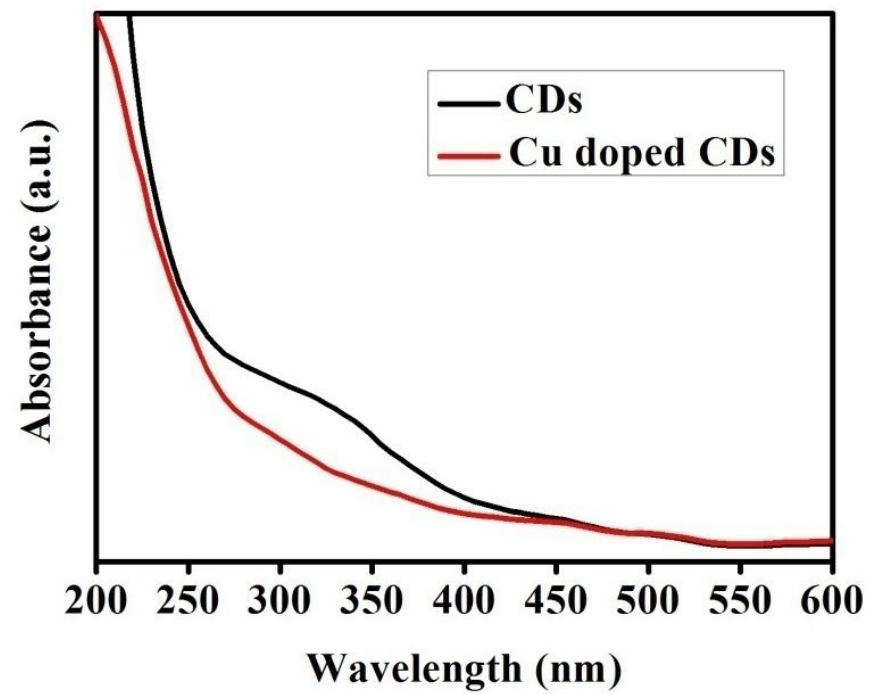

Figure S2. The UV-vis Spectrum of the As-prepared the Bare CDs and Cu-CDs. 


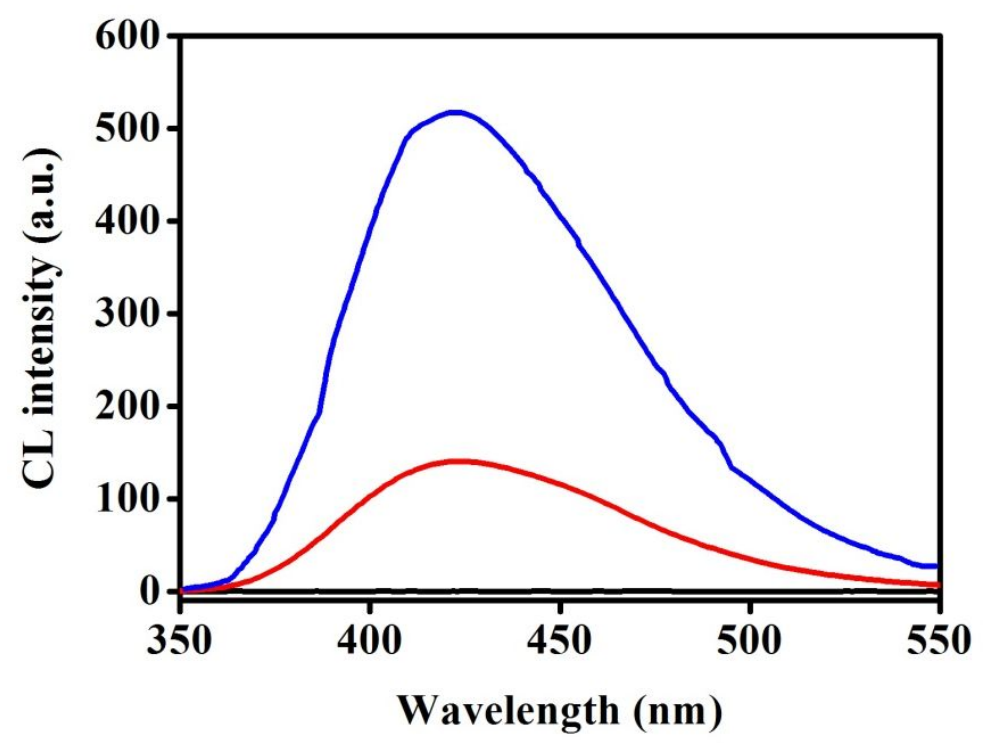

Figure S3. Feasibility of CL Biosensor Based Cu-CDs. Black Line: $\mathrm{H}_{2} \mathrm{O}_{2}+$ Luminol; Red Line: Luminol+Cu-CDs; Blue Line: $\mathrm{H}_{2} \mathrm{O}_{2}+$ Luminol $+\mathrm{Cu}-\mathrm{CDs}$. The Concentration of Luminol, $\mathrm{Cu}-\mathrm{CDs}$, and $\mathrm{H}_{2} \mathrm{O}_{2}$ was $0.75 \mathrm{mM}, 1.0 \mathrm{mg} \cdot \mathrm{mL}^{-1}, 1125 \mu \mathrm{M}$, Respectively.
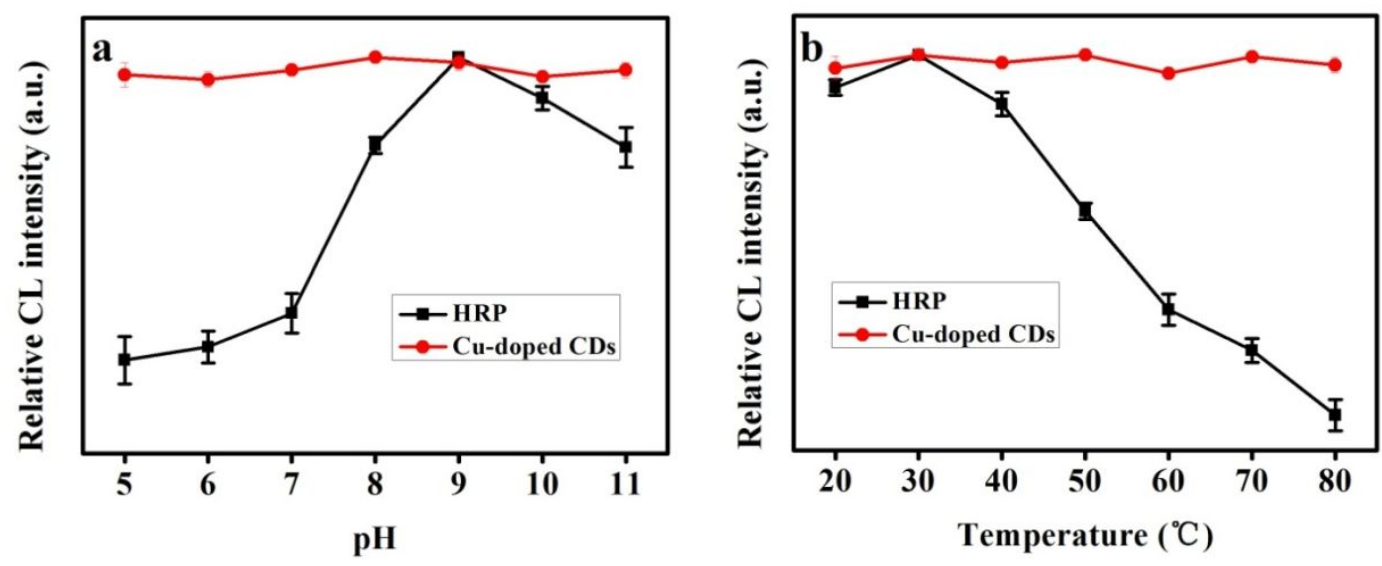

Figure S4. The Performance of the Catalytic Ability of HRP and Cu-CDs. 

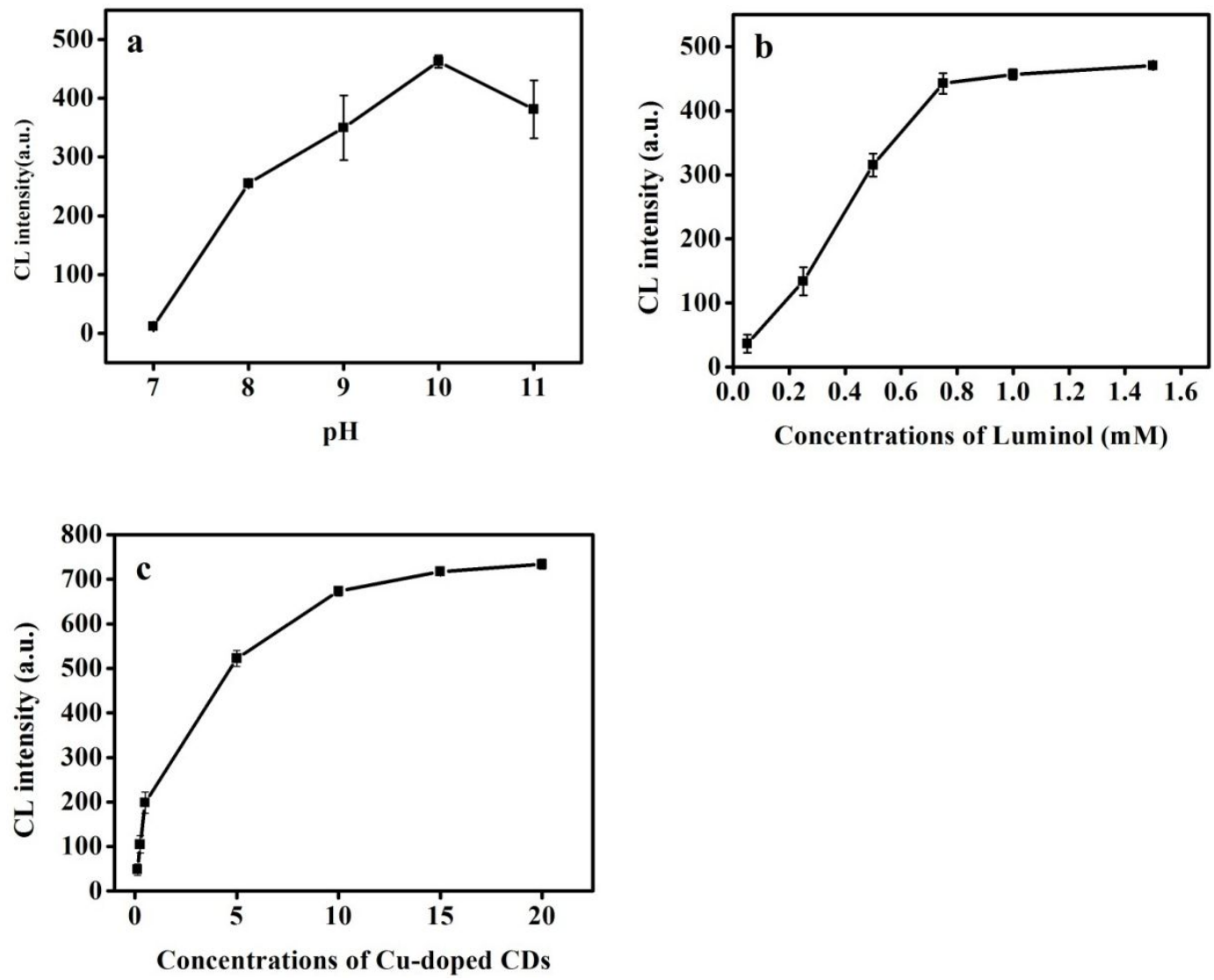

Figure S5. Effect of $\mathrm{pH}$ (a), Luminal (b) and Cu-CDs Concentration (c) on the Proposed CL Biosensor for the $\mathrm{H}_{2} \mathrm{O}_{2}$ Detection.

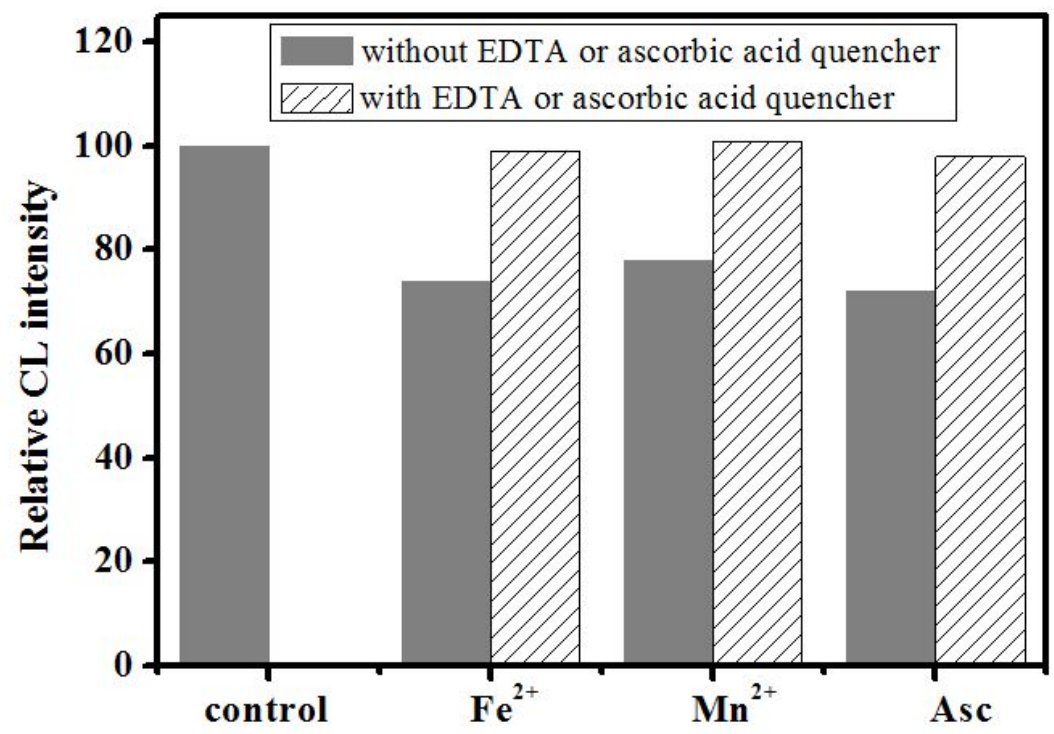

Fig. S6 CL intensity of the proposed CL system in the absence and in the presence of EDTA or 4-hydroxy-2,2,6,6-tetramethyl-N-oxygen-piperidine. Experimental conditions: $\mathrm{Fe}^{2+}, \mathrm{Mn}^{2+}$, and ascorbic acid (Asc) $40 \mu \mathrm{M}$; EDTA and 4-hydroxy-2,2,6,6-tetramethyl-N-oxygen-piperidine $2.5 \mathrm{mM}$. 
Table S1. Measure Value and Recoveries of the Determination of Glucose in Human Serum Samples Using the Proposed CL Sensor.

\begin{tabular}{cccccc}
\hline Sample & $\begin{array}{c}\text { Measure value } \\
\left(\mathrm{mmol} \cdot \mathrm{L}^{-1}\right)\end{array}$ & $\begin{array}{c}\text { Added } \\
\left(\mathrm{mmol} \cdot \mathrm{L}^{-1}\right)\end{array}$ & $\begin{array}{c}\text { Found } \\
\left(\mathrm{mmol} \cdot \mathrm{L}^{-1}\right)\end{array}$ & $\begin{array}{c}\text { Recovery } \\
(\%)\end{array}$ & $\begin{array}{c}\text { RSD } \\
(\%)\end{array}$ \\
\hline \multirow{2}{*}{ serum 1 } & 4.80 & 2.59 & 7.54 & 105.8 & 5.41 \\
& 4.80 & 4.61 & 9.37 & 99.1 & 8.16 \\
\multirow{2}{*}{ serum 2 } & 7.66 & 3.82 & 11.51 & 100.8 & 2.83 \\
& 7.66 & 7.26 & 15.46 & 107.4 & 6.57 \\
\multirow{2}{*}{ serum 3 } & 8.07 & 4.15 & 11.69 & 87.2 & 4.92 \\
& 8.07 & 6.04 & 14.85 & 112.2 & 6.55 \\
\hline
\end{tabular}

